\title{
Competition Law for a Complex Economy
}

\author{
Ioannis Lianos
}

Published online: 12 June 2019

(C) Max Planck Institute for Innovation and Competition, Munich 2019

As the global economy is incurring a process of transformation by the ongoing "fourth industrial revolution", competition law is traversing a "liminal" moment, a period of transition during which the normal limits to thought, self-understanding and behaviour are relaxed, opening the way to novelty and imagination, construction and destruction. ${ }^{1}$ The development of digital capitalism during the last three decades has led to an important "information overload", 2 induced by this rapid revolutionary change. Competition authorities in Europe and elsewhere have been rather slow to react, as they have tried unsuccessfully to deal with the problem by applying industrial-capitalism-era competition law to the "next generation competition" of the post-industrial informational capitalism.

Most competition law scholars have addressed this process of transformation by focusing on its technological dimension and its impact on business models. Their work usefully explores the ways the existing competition law framework may apply in order to address the technological challenges of the moment. Others have attempted to theorise the impact technology may have on the concept of competition in order to show that the current framework might be myopic. ${ }^{3}$ This effort has identified the problem but has not delved that deeply into suggesting a new theoretical framework for competition economics and competition law, and has

\footnotetext{
1 A. van Gennep, The Rites of Passage (Psychology Press 1960).

2 A. Toffler, Future Shock (Random House, 1970).

3 See, L. M. Khan, Amazon's Antitrust Paradox, (2017) 126(3) The Yale Law Journal p. 564; A. Ezrachi and M. Stucke, Virtual Competition (HUP, 2016).
}

\section{Lianos $(\bowtie)$}

Ph.D.; Professor of Global Competition Law and Public Policy and Director, Centre for Law, Economics and Society, UCL Faculty of Laws, London, UK

e-mail: i.lianos@ucl.ac.uk

\section{Lianos}

Academic Director, BRICS Competition Law and Policy Centre, HSE, Moscow, Russia 
stopped short in offering new operational concepts that could be integrated in positive law.

All these initiatives to a certain extent strive to address the question of the scope, role and function of competition law in the post-industrial capitalism era. However, they have not so far integrated this question in the broader debate over the new processes of value generation and capture in the era of digital capitalism and the complex economy to which it has given rise. A complex economy is formed by a web of economic links, but also their underpinning societal relations, between different agents whose actions interconnect through feedback loops in different ways. It forms a dynamic system of interacting agents characterised by constant adaptive learning. It is also nonlinear, to the extent that small changes in its parameters may produce large changes in behaviour, as various interdependent feedback loops affect individual decisions across the different parts of the system. In order to understand this emergent non-deterministic behaviour, one needs to refer to concepts such as increasing returns, leverage points, tipping points and path dependence. However, competition law still lives in the simple world of neoclassical price theory (NPT) economics, populated by representative agents that operate according to the rational choice model with prices signalling their preferences in the context of well-defined markets as the exclusive focus of NPT's partial equilibrium thinking. This framework does not engage with the dynamic complexity of the economy, with the computational complexity of the agents, a heterogeneous group not only composed by individuals but also by organisations, and with the connective complexity of the interactions between these agents. ${ }^{4}$ The emphasis put recently by competition authorities on multi-sided markets in order to analyse restrictions of competition in the data economy illustrates the agents' changing roles and the complexity of their interactions, as the same agents can be at the same time consumers and producers while their personal data is raw material for the value generation process.

It becomes therefore essential to uncover the value capture and value generation processes in operation in the digital economy, and draw lessons for the optimal design and enforcement of competition law, rather than taking the established competition law framework as a given and trying to stretch within it a quite complex reality that may not fit this Procrustean iron bed. The challenge of fitting multi-sided markets theory in the context of a kind of loose market definition as a transaction platform or of determining the existence of a restriction of competition by effect, but facing the difficult consideration of out-of-market efficiencies, provides an illustration of the inherent difficulties, and ultimately of the futility, of such an exercise. Instead, competition law should focus on the way the value brought by innovation in the digital economy is captured, shared and generated - the three processes being intrinsically linked. How does this process affect the competitive strategies of firms and the broader selection environment in the economy? I identify three important manifestations of this complexity that may have significant implications for competition law in the years to come.

\footnotetext{
${ }_{4}^{4}$ J. Foster, From simplistic to complex systems in economics, (2005) 29 Cambridge Journal of Economic p. 873.
} 
The first relates to "futurity", a term originally coined by John R. Commons to describe the reorientation of economies towards the future. This is linked to the fledgling practice of treating businesses as "going concerns", measuring their value in terms of their anticipated future profits. In today's financialised digital economy the most important driver of value creation is pots of gold being found far into the future and eventually linked to future expected monopolistic rents. The futurity trend is particularly salient in the funding of blockchain technology projects with Initial Coin Offerings (ICOs) emerging as the main source of funding for blockchain start-ups, even before any promise in their "white paper" has materialised in real product markets. Digital platforms are also "madly" valued by financial markets, in a way that does not seem to correspond to their current cash flow, but which increasingly relates to high expectations for phenomenal profits in the not-soimmediate future because of their position as gatekeepers controlling important bottlenecks in the digital economy (e.g. operating systems, search engines, app stores, the cloud). ${ }^{5}$ The relatively recent focus of competition law on innovation, rather than allocative efficiency, also provides an additional example of the impact of futurity, this time in competition law doctrine. Futurity, and its linkage to financialisation, challenges the traditional approach of competition law to focus on market power perceived as the ability to raise prices and reduce output in a welldelineated and existing product market.

Second, the harvesting and processing of personal data enables the personalisation of both production and distribution. It is increasingly acknowledged that data collection is key in the ability of firms to compete in the future Internet of Things or Internet of Services. Firms harvest personal data by attracting users and monetise this data in advertising "attention markets". Although consumers often do not pay for the zero-priced products provided by the platforms, other than by providing their data, their autonomy to self-determine the level of privacy they enjoy is curtailed by the "take-it-or-leave-it" nature of their exchanges with digital platforms, on which they are dependent in order to operate (work, develop social interactions, be entertained) in their daily life. ${ }^{6}$ Consumers cannot easily and without cost escape from this technological dependence by switching to alternative options, in view of the high switching costs, the fact that they may not be able to port all their data and digital relations to the competing platform, and the lack of competition resulting from the "winner-takes-most" nature of most of these markets. Data analytics connected to the use of software for predictive modelling will also reinforce the competitive advantages for the digital platforms holding most of the data, or the attention of users, this being ultimately crystallised in "architectural advantage", thus entrenching their monopoly and/or monopsony position in the value chain. ${ }^{7}$ Much of this data will relate to the digital identity of the consumer and will enable

\footnotetext{
5 See, https://www.economist.com/business/2017/02/23/are-technology-firms-madly-overvalued.

6 The recent Facebook case of the Bundeskartellamt has put forward.

7 M. Jacobides, S. Winter and S. Kassberger, "The Dynamics of Wealth, Profit, and Sustainable Advantage", (2012) 33 Strategic Management Journal, p. 1386.
} 
companies to draw fairly accurate preference maps for each of their clients. In this era of "mass personalisation" 8 the focus will not only be on "attention markets", 9 but on the development of bespoke products to the individual preferences of the consumers. Once a specific amount of data is harvested, these personalised markets may tip to a monopoly if only one platform or ecosystem has the capabilities to harvest and analyse the data as well as to perfectly satisfy the individual consumer's demand function in an array of products. Firms may be able to monetise this power in financial markets and to leverage it or convert it in other spheres of social activity (e.g. political power, cultural power). Firms may also use this privileged access to the "mind" and attention of users in order to reinforce their positional advantage in the specific value chain vis-à-vis firms forming part of their value ecosystem and which are dependent on them to reach these users.

The third important change is the move from markets to cybernetics. In the static model of competition applied by competition authorities, prices provide complex information in a condensed way to producers about consumer preferences, thus enabling conventional markets to work. The new data harvesting and processing techniques are nonetheless important game-changers. First, the use of data improves market matches. As customers keep shopping, digital assistants learn how to make even better recommendations, most of this "learning" taking place completely or largely unassisted by humans, as data is fed into machines that continuously update their algorithms. Algorithmic firms gather comprehensive personal data on their customers, and by doing so they undo the need to rely on decentralised markets to acquire knowledge on the preferences of consumers. Preferences do not materialise through choice but are algorithmically predicted. Second, they may also more easily discriminate between groups of consumers/users by choosing a price structure that would subsidise some and "tax" with higher prices others or by offering a personalised price. Price loses its central position as an indicator of consumer preferences expressed in decentralised markets. Consumers are not in the driver's seat, as buyers are influenced both by explicit recommendations and by the ways in which options are filtered and presented, in particular as their "trust in the machine" may be higher than trust in humans. Digital platforms may thus replace markets to a certain extent, in particular in a "winner-takes-most" world where, in the presence of strong network effects, digital markets may easily "tip". Platforms do not just "match" different groups of users but become prediction machines with the ability to manipulate or influence users' choice. The way these digital platforms finish by regulating their ecosystems, but also manage consumer demand, presents some similarities to a private version of a centrally-planned mini-economy and the field of cybernetics.

These considerations lead me to advance a different approach in exploring competition law in the digital era.

\footnotetext{
${ }^{8}$ Deloitte, "Made to Order: The Rise of mass personalisation" (2015), available at https://www2. deloitte.com/content/dam/Deloitte/uk/Documents/consumer-business/deloitte-uk-consumer-review-masspersonalisation.pdf.

${ }^{9}$ On this concept, see T. Wu, Blind Spot: The Attention Economy and the Law (March 26, 2017). Antitrust Law Journal, Forthcoming. Available at SSRN: https://ssrn.com/abstract=2941094; D. S. Evans, The Economics of Attention Markets (October 31, 2017). Available at SSRN: https://ssrn.com/abstract= 3044858.
} 
- First, the complexity of the production process highlights the importance of conducting a careful analysis of the power relations along the digital value chain, and not only between different value chains, the aim being to unveil value extraction bottlenecks affecting the distribution of the total surplus value generated by digital innovation. Beyond the economic motives of such an approach, ${ }^{10}$ I consider that because of the important social implications of the transition to digital capitalism, and the important tensions to social stability this may engender, it becomes important to analyse the distributional implications of competition law enforcement. This analysis cannot always be undertaken by the traditional NPT approach, which mainly focuses on horizontal competition (market power) and economic efficiency. Competition law scholarship should critically engage with the dual role of competition law as economic and social regulation, the main purpose of which being to tame economic power not only driven by economic efficiency considerations but also by social justice. ${ }^{11}$ The NPT framework also ignores "vertical competition", the competition for a higher percentage of the surplus value brought by innovation, and competition from complementary technologies that may challenge the lead position in the value chain of the incumbents (vertical innovation competition). We also need to consider the multiple dimensions and sources of "economic power", horizontal and vertical, in the digital economy (e.g. intermediary power, algorithmic power, architectural power). ${ }^{12}$

- Second, data and network effects require us to rethink competitive interactions beyond the traditional concept of relevant market. Some have put forward the view that the competition assessment should be done at the level of the platform. ${ }^{13}$ This may nevertheless challenge the important role of competitive markets as the main social institution to reward productivity. Competition law also needs to engage with the various forms of the competitive struggle to gain not only competitive advantage on product markets but also acquire architectural advantage, which is often more highly valued by financial markets, in view of its potential to sustain abnormal returns for a longer period of time. Developed in the early 1990s, ${ }^{14}$ the concept of "ecosystem" provides important insights in order to understand digital competition. ${ }^{15}$ The "eco-system manager"

\footnotetext{
${ }^{10}$ These are examined in a separate publication: I. Lianos, Regulating Digital Value Chains: Implications for Competition Law, CLES Research paper series 1/2019.

11 See, I. Lianos, "The Poverty of Competition Law" (CLES Research Paper 2/2018), available at https:// papers.ssrn.com/sol3/papers.cfm?abstract_id=3160054.

12 This derives from the central position of the agent in the network of various agents involved in this socio-technical system and capabilities to set the agenda for the rest of the network. I explore this further in I. Lianos et al., Superior Bargaining Power in Competition Law: A Theoretical Analysis, in I. Lianos, A. Ivanov and D. Davis, (eds.) Global Food Value Chains and Competition Law: Towards Holistic Competition Law? (forth. CUP, 2019); and in I. Lianos, V. Korah with P. Siciliani, Competition Law: Analysis, Cases and Materials (OUP, 2019), Chapter 8.

13 See, the majority opinion of the Supreme Court in Ohio v. American Express, 138 S.Ct. 2274 (2018).

14 J. F. Moore, Predators and prey: A new ecology of competition, (1993) 71(3) Harvard Business Review p. 75.

15 M. Jacobides, C. Cennano and A. Gawer, Towards a theory of ecosystems, (2018) 39 Strategic Management Journal p. 2255.
} 
determines the elements of the value chain that need to be internalised and which elements will be supported externally so as to capture value. Competition analysis should engage with the "value capture strategies" put in place by economic actors competing for strategic or architectural advantage. ${ }^{16}$ Abandoning the sole focus on the relevant market also stems from the relatively more limited role of price competition in the digital economy (e.g. "free goods" and multi-sided markets strategies). Hence, we need to develop new mapping tools that represent more accurately horizontal and vertical competitive interactions in the digital economy. ${ }^{17}$

- Third, the broader array of interactions, beyond market exchanges, between the different stakeholders, invites us to broaden our understanding of competition law, beyond the monocentric model focusing on price and output that has so far prevailed. In understanding the role of competition law in this new environment, some prominent authors have suggested a "broader reach for competition policy" 18 that would engage with the full social costs engendered by restrictions of competition on different dimensions of well-being. Competition law will have to acquire a polycentric dimension in order to guarantee the effective protection of the societal values that may be affected by actors with economic power. ${ }^{19}$ However, we crucially lack the operational concepts, tools and metrics to develop this agenda further. Traditional equation-based modelling, although rigorous and insightful, may not cater for these very complex systems. We need to draw on the broader conceptual and methodological framework of "complex economics" 20 which, I think, provides very interesting conceptual and practical insights in order to operationalise the complex systems that it becomes necessary to consider as competition law moves to tackle digital competition.

Publisher's Note Springer Nature remains neutral with regard to jurisdictional claims in published maps and institutional affiliations.

\footnotetext{
${ }^{16}$ D. Teece, Business models, value capture, and the digital enterprise, (2017) 6:8 Journal of Organizational Design.

17 See, Global Food Value Chains and Competition Law - BRICS Draft Report (January 1, 2018). Available at SSRN: https://ssrn.com/abstract=3076160 or http://dx.doi.org/10.2139/ssrn.3076160; I. Lianos, Digital Value Chains in Competition Law (CLES Research Paper 1/2019), available at https:// www.ucl.ac.uk/cles/research-papers.

18 J. Stiglitz, Towards a Broader View of Competition Policy, in Tembinkosi Bonakele, Eleanor Fox, and Liberty Mncube (eds.), Competition Policy for the New Era: Insights from the BRICS countries (OUP, 2016).

19 I. Lianos, Polycentric Competition Law, (2018) Current Legal Problems p. 161.

${ }^{20}$ See, inter alia, W. B. Arthur, Complexity and the Economy (OUP, 2015); D. S. Wilson and Alan Kirman (eds.), Complexity and Evolution - Towards a New Synthesis for Economics (MIT Press, 2016).
} 